\title{
Re-assessing ZNF331 as a DNA methylation biomarker for colorectal cancer
}

\author{
Hege Marie Vedeld ${ }^{1,2}$, Arild Nesbakken ${ }^{2,4,5}$, Ragnhild A. Lothe ${ }^{1,2,5}$ and Guro E. Lind ${ }^{1,2,3^{*}}$ (D)
}

\begin{abstract}
We have previously shown that aberrant promoter methylation of ZNF331 is a potential biomarker for colorectal cancer detection with high sensitivity (71\%) and specificity (98\%). This finding was recently confirmed by others, and it was additionally suggested that promoter methylation of ZNF331 was an independent prognostic biomarker for colorectal cancer $(n=146)$. In the current study, our initial colorectal cancer sample series was extended to include a total of 423 cancer tissue samples. Aberrant promoter methylation was found in $71 \%$ of the samples, thus repeatedly suggesting the biomarker potential of ZNF331 for detection of colorectal cancer. Furthermore, multivariate Cox's analysis indicated a trend towards inferior overall survival for colorectal cancer patients with aberrant methylation of ZNF331.
\end{abstract}

Keywords: Colorectal cancer, Diagnosis, DNA methylation, Prognosis, ZNF331

\section{Introduction}

In cancer, increased promoter DNA methylation is a frequent event commonly occurring early in tumor development. Methylated DNA sequences may serve as tumor biomarkers in liquid biopsies for detecting cancer and for predicting patient prognosis [1].

In 2011, we filed a patent application covering methylation of ZNF331 (Zinc finger protein 331) as a biomarker for gastrointestinal cancers [2]. ZNF331 was shown by Yu et al. to be inactivated by promoter methylation in gastric cancer, providing the cancer cells with increased growth potential and invasiveness [3]. We also found a high methylation frequency in patients with gastric cancer $(80 \%)$ and to a lesser extent in patients with pancreatic cancer (40\%) and cholangiocarcinomas (26\%) [4]. Most importantly, we reported high sensitivity (71\%) and specificity (98\%) for ZNF331 methylation in colorectal cancer early 2015, strengthening the potential of ZNF331 as a biomarker for colorectal cancer detection [4]. Interestingly, these findings were recently confirmed, further supporting the biomarker potential of ZNF331 in colorectal cancer [5]. The same study also suggested aberrant promoter

\footnotetext{
* Correspondence: guro.elisabeth.lind@rr-research.no

${ }^{1}$ Department of Molecular Oncology, Institute for Cancer Research, Oslo

University Hospital-Norwegian Radium Hospital, Oslo, Norway

${ }^{2}$ K.G. Jebsen Colorectal Cancer Research Centre, Oslo University Hospital,

Oslo, Norway

Full list of author information is available at the end of the article
}

methylation of ZNF331 as an independent prognostic marker for colorectal cancer, analyzing 146 samples [5]. In the present study, we analyzed the effect of ZNF331 methylation on overall survival, including altogether 423 colorectal tissue samples.

\section{Results and discussion}

Methylation of the ZNF331 promoter was found in 71\% (301/423) of the patients with colorectal cancer and was associated with localization in the right colon, microsatellite instability (MSI), and the BRAF $F^{V 600 E}$ mutation. Furthermore, ZNF331 methylation was strongly associated with CpG island methylator phenotype (CIMP) and MLH1 methylation (Table 1). Wang et al. [5] reported a similar methylation frequency of ZNF331 in colorectal cancer (67\%; 98/146). However, in contrast to our data Wang et al. did not find associations between methylated ZNF331 and BRAF mutation, CIMP nor $M L H 1$ methylation, which may be explained by differences in sample size (Wang et al., $n=146$; current study, $n=423$ ), marker panels to define CIMP, method to identify methylation, age (median age Wang et al. 60; current study 72), and/or ethnicity (Wang et al.: Asian; current study: Caucasian).

Wang et al. [5] further reported that patients with ZNF331 promoter methylation had a worse prognosis than patients with unmethylated promoters. Our results were in accordance with their study, although statistical 
Table 1 Associations between ZNF331 methylation and clinical and molecular features

\begin{tabular}{|c|c|c|c|c|}
\hline & $\begin{array}{l}\text { Total } \\
n\end{array}$ & $\begin{array}{l}\text { ZNF331 unmethylated } \\
n(\%)\end{array}$ & $\begin{array}{l}\text { ZNF331 methylated } \\
n(\%)\end{array}$ & $P$ value \\
\hline No. of patients & 423 & $122(29)$ & $301(71)$ & \\
\hline Gender & & & & 0.165 \\
\hline Male & 213 & $68(32)$ & $145(68)$ & \\
\hline Female & 210 & $54(26)$ & $156(74)$ & \\
\hline Age & & & & 0.074 \\
\hline$<60$ & 70 & $26(37)$ & $44(63)$ & \\
\hline $60-74$ & 178 & $55(31)$ & $123(69)$ & \\
\hline$\geq 75$ & 175 & $41(23)$ & $134(77)$ & \\
\hline Stage & & & & 0.683 \\
\hline I & 79 & $20(25)$ & $59(75)$ & \\
\hline$\|$ & 169 & $51(30)$ & $118(70)$ & \\
\hline III & 118 & $32(27)$ & $86(73)$ & \\
\hline IV & 56 & 19 (34) & $37(66)$ & \\
\hline Localization & & & & $<0.001$ \\
\hline Right colon & 167 & $27(16)$ & $140(84)$ & \\
\hline Left colon & 130 & $47(36)$ & $83(64)$ & \\
\hline Rectum & 121 & $46(38)$ & $75(62)$ & \\
\hline MSI status & & & & $<0.001$ \\
\hline MSS & 325 & $111(34)$ & $214(66)$ & \\
\hline MSI & 89 & $8(9)$ & $81(91)$ & \\
\hline BRAF & & & & $<0.001$ \\
\hline BRAF wt & 356 & $120(34)$ & $236(66)$ & \\
\hline BRAF mut & 67 & $2(3)$ & $65(97)$ & \\
\hline CIMP & & & & $<0.001$ \\
\hline CIMP- & 355 & $121(34 \%)$ & $234(66)$ & \\
\hline CIMP+ & 65 & $0(0)$ & $65(100)$ & \\
\hline MLH1 methylation & & & & $<0.001$ \\
\hline MLH1 unmeth & 360 & 117 (32.5) & $243(67.5)$ & \\
\hline MLH1 meth & 60 & $4(7)$ & $56(93)$ & \\
\hline Series & & & & 0.439 \\
\hline Oslo 3 & 59 & $14(24)$ & $45(76)$ & \\
\hline Oslo 2 & 364 & $108(30)$ & $256(70)$ & \\
\hline
\end{tabular}

Meth methylated, mut mutation, No. number, unmeth unmethylated, wt wild type

significance was not reached in the multivariate Cox regression model adjusting for age and stage $(\mathrm{HR}=1.44$ $(0.97-2.14), P=0.069$; Table 2). The univariate model is presented in Fig. $1(P=0.143)$.

In conclusion, in an extended series of colorectal cancer samples, we have showed the potential of promoter methylation of ZNF331 as a biomarker for colorectal cancer detection. We have further provided data indicating a trend towards poorer prognosis for patients with ZNF331 methylation.

\section{Material and methods}

\section{Colorectal cancer tissue samples}

This study included 423 colorectal cancer tissue samples. Fifty-nine of the samples were obtained from several different hospitals in the southeast region of Norway in the period 1987-1989 (Oslo 3 series; described in [6]), and 364 of the samples were obtained from patients undergoing surgical resection at the Oslo University Hospital-Aker from 2005 to 2011 (Oslo 2 series; described in $[7,8]$ ). Survival data was available for 419 patients (Oslo 3, $n=59$; Oslo 2, $n=360$ ). 
Table 2 Multivariate Cox proportional hazard analysis with overall survival as endpoint

\begin{tabular}{llll}
\hline & Patients, $n$ & Multivariate HR $(95 \% \mathrm{Cl})$ & $P$ value \\
\hline Age & & & \\
$<60$ & 70 & $1.00($ ref $)$ & \\
$60-74$ & 176 & $1.70(0.91-3.18)$ & 0.099 \\
$\geq 75$ & 173 & $3.42(1.84-6.34)$ & $<0.001$ \\
Stage & & & \\
I & 78 & $1.00($ ref $)$ & 0.498 \\
II & 168 & $1.24(0.66-2.34)$ & 0.009 \\
III & 117 & $2.32(1.24-4.34)$ & $<0.001$ \\
IV & 56 & $11.10(5.91-20.85)$ & \\
ZNF331 methylation & & & 0.069 \\
ZNF331 unmeth & 121 & $1.00($ ref $)$ & \\
ZNF331 meth & 298 & $1.44(0.97-2.14)$ & \\
\hline
\end{tabular}

Variables not selected by the backward likelihood method to be included in the final model: series, gender, CIMP-, MSI-, and BRAF mutation status Meth methylated, unmeth unmethylated

\section{Bisulfite treatment and quantitative methylation-specific PCR (qMSP)}

DNA from cancer tissue samples were bisulfite treated using the EpiTect Bisulfite Kit (Qiagen), and the samples were purified using the QIAcube (Qiagen).

Quantitative methylation-specific PCR (qMSP) was used to analyze the methylation of the ZNF331 promoter (NM_018555), with primers and probe sequences as reported earlier [4]. The method was performed as previously described [4, 9], with the ALU-C4 element as a

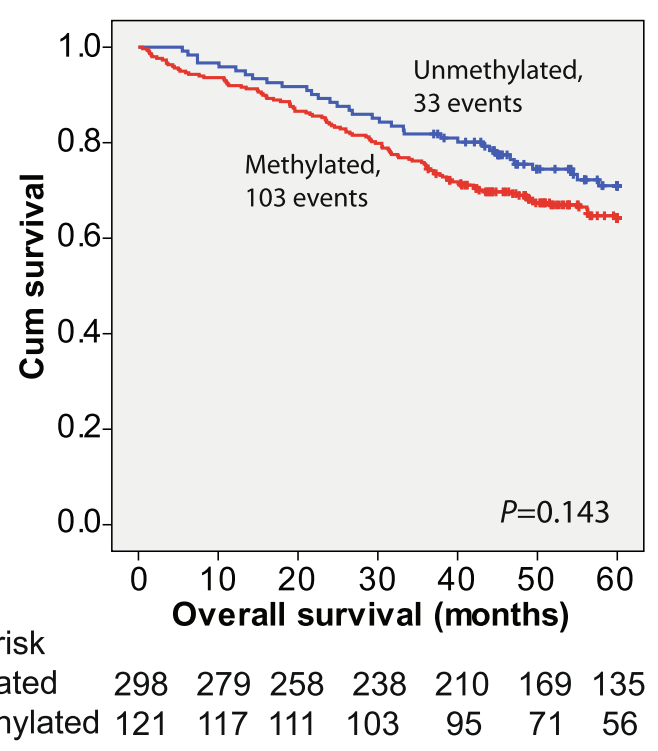

No. at risk

$\begin{array}{llllllll}\text { Methylated } & 298 & 279 & 258 & 238 & 210 & 169 & 135\end{array}$ Unmethylated $\begin{array}{lllllll}121 & 117 & 111 & 103 & 95 & 71 & 56\end{array}$

Fig. 1 Effect of ZNF331 promoter methylation on overall survival modeled by the Kaplan-Meier method and compared using the log-rank test normalization control [10]. As described in ref. [4], samples with percent methylated reference (PMR) values $\geq 1$ were considered methylated. Information about MSI, CIMP, MLH1 methylation, and BRAF mutation status were available from previous studies $[11,12]$.

\section{Statistical analyses}

Associations between ZNF331 methylation and clinicopathological data were analyzed by Pearson chi-square or Fisher's exact tests. For all analyses, patients were divided into three age groups ( $<60$ years, $60-74$ years, and $\geq 75$ years). Breakpoints were chosen as previously described [11]. Overall survival was used as endpoint in the survival analyses and was calculated from time of surgery until death of any cause. Cases were censored at last follow-up. The univariate effect of ZNF331 on survival was modeled by the Kaplan-Meier method and compared using the log-rank test. A multivariate Cox's proportional hazard model was generated by a stepwise selection procedure (backward likelihood model) in order to identify a subset of relevant predictor variables from the set of available clinicopathological data (series, age, stage, gender, CIMP-, MSI-, BRAF-, and ZNF331 methylation status). Hazard ratios (HRs) and 95\% confidence intervals (CIs) were derived from the model, and significance of the parameters was assessed using Wald's test. To evaluate the assumption of proportionality, a chi-square test was performed. A $P$ value $<0.05$ was considered statistically significant. The analyses were performed using IBM SPSS Statistics 21 and R version 3.4.1.

\section{Abbreviations}

CIMP: CpG island methylator phenotype

\section{Funding}

This work was supported by grants from the South-Eastern Norway Regional Health Authority (project number 2016071 to G.E. Lind, funding HM Vedeld as a postdoc)

\section{Availability of data and materials}

The datasets generated and analyzed during the current study are not publicly available but are available from the corresponding author on reasonable request.

\section{Authors' contributions}

GEL contributed to the conception and design. HMV, AN, and RAL contributed to the acquisition of data. HMV, AN, RAL, and GEL contributed to the analyses and interpretation of the data. HMV contributed to the drafting of the manuscript. All authors were involved in the revision of the manuscript and have approved the final version.

\section{Ethics approval and consent to participate}

The research biobanks have been registered according to national legislation (numbers 2781 and 236-2005-16141). The study is part of a project approved by the Regional Committee (REC) for Medical and Health Research Ethics (numbers 1.2005.1629 and S-09282c 2009/4958).

\section{Competing interests}

RAL and GEL are inventors of a US provisional patent application filed in 2011, describing methylation of ZNF331 and five additional genes as biomarkers for detection of gastrointestinal cancers (61/451,198, INVEN- 
31899/US-1/PRO). The rest of the authors declare that they have no competing interests.

\section{Publisher's Note}

Springer Nature remains neutral with regard to jurisdictional claims in published maps and institutional affiliations.

\section{Author details}

'Department of Molecular Oncology, Institute for Cancer Research, Oslo University Hospital-Norwegian Radium Hospital, Oslo, Norway. ${ }^{2}$ K.G. Jebsen Colorectal Cancer Research Centre, Oslo University Hospital, Oslo, Norway. ${ }^{3}$ Department of Biosciences, Faculty of Mathematics and Natural Sciences, University of Oslo, Oslo, Norway. ${ }^{4}$ Department of Gastrointestinal Surgery, Oslo University Hospital-Aker, Oslo, Norway. ${ }^{5}$ Institute for Clinical Medicine, Faculty of Medicine, University of Oslo, Oslo, Norway.

\section{Received: 21 December 2017 Accepted: 15 May 2018}

\section{Published online: 29 May 2018}

\section{References}

1. Vedeld HM, Goel A, Lind GE. Epigenetic biomarkers in gastrointestinal cancers: the current state and clinical perspectives. Semin Cancer Biol. 2017; https://doi.org/10.1016/j.semcancer.2017.12.004.

2. Lothe RA, Ahmed D, Andresen K et al. Methods and biomarkers for detection of gastrointestinal cancers. US provisional application filed 61/451,198, INVEN-31899/US-1/PRO 2011.

3. Yu J, Liang QY, Wang J, et al. Zinc-finger protein 331 , a novel putative tumor suppressor, suppresses growth and invasiveness of gastric cancer. Oncogene. 2012;32:307-17.

4. Vedeld HM, Andresen $\mathrm{K}$, Eilertsen IA, et al. The novel colorectal cancer biomarkers CDO1, ZSCAN18 and ZNF331 are frequently methylated across gastrointestinal cancers. Int J Cancer. 2015;136:844-53.

5. Wang Y, He T, Herman JG, et al. Methylation of ZNF331 is an independent prognostic marker of colorectal cancer and promotes colorectal cancer growth. Clin Epigenetics. 2017:9:115.

6. Lothe RA, Peltomaki P, Meling Gl, et al. Genomic instability in colorectal cancer: relationship to clinicopathological variables and family history. Cancer Res. 1993;53:5849-52.

7. Sveen A, Agesen TH, Nesbakken A, et al. ColoGuidePro: a prognostic 7-gene expression signature for stage III colorectal cancer patients. Clin Cancer Res. 2012;18:6001-10.

8. Berg M, Danielsen SA, Ahlquist T, et al. DNA sequence profiles of the colorectal cancer critical gene set KRAS-BRAF-PIK3CA-PTEN-TP53 related to age at disease onset. PLoS One. 2010;5:e13978

9. Lind GE, Danielsen SA, Ahlquist T, et al. Identification of an epigenetic biomarker panel with high sensitivity and specificity for colorectal cancer and adenomas. MolCancer. 2011;10:85.

10. Weisenberger DJ, Campan M, Long Tl, et al. Analysis of repetitive element DNA methylation by MethyLight. Nucleic Acids Res. 2005;33:6823-36.

11. Vedeld HM, Merok $M$, Jeanmougin $M$, et al. CpG island methylator phenotype identifies high risk patients among microsatellite stable BRAF mutated colorectal cancers. Int J Cancer. 2017;141:967-76.

12. Merok MA, Ahlquist T, Royrvik EC, et al. Microsatellite instability has a positive prognostic impact on stage II colorectal cancer after complete resection: results from a large, consecutive Norwegian series. Ann Oncol. 2013;24:1274-82.

\section{Ready to submit your research? Choose BMC and benefit from:}

- fast, convenient online submission

- thorough peer review by experienced researchers in your field

- rapid publication on acceptance

- support for research data, including large and complex data types

- gold Open Access which fosters wider collaboration and increased citations

- maximum visibility for your research: over $100 \mathrm{M}$ website views per year

At BMC, research is always in progress.

Learn more biomedcentral.com/submissions 